\title{
Reduced Rates of Hypoglycemia in Type 1 or Type 2 Diabetes After Switching to Insulin Degludec: Results from the Italian Cohort of the ReFLeCT Study
}

\author{
Gian Paolo Fadini (D) C Carla Giordano · Laura Salvi · Antonio Nicolucci on behalf of The REFLECT Italian Study \\ Group
}

Received: July 27, 2020 / Accepted: September 19, 2020 / Published online: October 3, 2020

(C) The Author(s) 2020

\section{ABSTRACT}

Introduction: To evaluate in an Italian realworld setting the safety and effectiveness of insulin degludec 100 units/mL, given once daily in patients with type 1 diabetes mellitus (T1DM) and type 2 diabetes mellitus (T2DM) after switching from other basal insulins.

Methods: ReFLeCT was a multicenter, prospective, observational study conducted across seven European countries which involved adult

The full list of Italian sites participating in this study (contact name, site name, city) can be found in the Electronic Supplementary Material.

Electronic Supplementary Material The online version of this article (https://doi.org/10.1007/s13300020-00936-5) contains supplementary material, which is available to authorized users.

G. P. Fadini $(\square)$

Department of Medicine, University of Padova, Padua, Italy

e-mail: gianpaolo.fadini@unipd.it

C. Giordano

Section of Endocrinology, Diabetology and Metabolism, Biomedical Department of Internal and Specialist Medicine (DIBIMIS), University of Palermo, Palermo, Italy

L. Salvi

Novo Nordisk Spa, Rome, Italy

A. Nicolucci

The Center for Outcomes Research and Clinical

Epidemiology (CORESEARCH), Pescara, Italy patients whose physician planned to switch their medication from basal insulin to insulin degludec. The primary outcome was the change in the number of hypoglycemic episodes before and after the switch to insulin degludec. Results are expressed as 12-month follow-up/baseline incidence rate ratios (IRRs) with 95\% confidence intervals (95\% CIs).

Results: The Italian cohort of the ReFLect study comprised 148 patients with T1DM and 311 patients with T2DM. In patients with T1DM, the switch to insulin degludec was associated with significantly lower rates of overall (IRR 0.69, 95\% CI 0.57-0.82), non-severe (IRR 0.72 , 95\% CI $0.60-0.85$ ), and nocturnal hypoglycemia (IRR 0.46, 95\% CI 0.31-0.69). Following the switch, hemoglobin $\mathrm{A}_{1 \mathrm{c}}\left(\mathrm{HbA}_{1 \mathrm{c}}\right)$ levels decreased significantly by $0.35 \%$ (95\% CI -0.50 to -0.20 ), with no significant changes in fasting plasma glucose (FPG) and basal insulin dose. Body weight increased by $0.83 \mathrm{~kg}(95 \%$ CI 0.16-1.50). In patients with T2DM, significant reductions in the rates of overall (IRR 0.40, 95\% CI 0.29-0.55), non-severe (IRR 0.47, 95\% CI 0.34-0.63), and nocturnal hypoglycemia (IRR 0.27, 95\% CI 0.09-0.86) were documented. $\mathrm{HbA}_{1 \mathrm{c}}$ and FPG decreased significantly by $0.45 \%$ (95\% CI -0.58 to -0.31$)$ and $0.90 \mathrm{mmol} / \mathrm{L}$ (95\% CI -1.21 to -0.59 ], respectively, with no significant changes in basal insulin dose or body weight. Treatment satisfaction significantly improved in both diabetes types. 
Conclusion: In Italian routine clinical practice, switching from other basal insulins to insulin degludec reduced the total episodes of hypoglycemia and improved glycemic control and treatment satisfaction in patients with T1DM and T2DM.

Trial

Registration: ClinicalTrials.gov

NCT02392117.

Keywords: Hypoglycemia; Insulin degludec; Treatment satisfaction; Type 1 diabetes; Type 2 diabetes

\section{Key Summary Points}

Why carry out this study?

The multinational ReFLeCT study showed that switching treatment to degludec reduced hypoglycemia rates in patients with type 1 or type 2 diabetes.

We have examined results in the Italian cohort of the study.

In the very homogeneous Italian cohort of patients with type 1 or type 2 diabetes we verified if switching treatment to degludec would reduce hypoglycemia rates and improve glucose control.

\section{What was learned from the study?}

Results from the Italian cohort confirm those from the multinational study showing greater benefits of degludec.

In addition to lowering hypoglycemia rates, switching to degludec improved hemoglobin $\mathrm{A}_{1 \mathrm{c}}$.

\section{DIGITAL FEATURES}

This article is published with digital features to facilitate understanding of the article. To view digital features for this article go to https://doi. org/10.6084/m9.figshare.12974507.

\section{INTRODUCTION}

Key treatment goals in patients with either type 1 or type 2 diabetes mellitus (T1DM, T2DM) are the achievement and maintenance of patientspecific, adequate glycemic control to reduce long-term complications. However, hypoglycemia is a significant barrier to tight glycemic control, often leading to therapeutic inertia [1]. Hypoglycemia is also responsible for a negative impact on patient quality of life, treatment adherence, and work productivity $[2,3]$. Consequently, minimizing the number and severity of hypoglycemic episodes is a key priority for diabetes care.

Insulin degludec is a basal insulin analog with a duration of action exceeding $42 \mathrm{~h}$ at steady state and a lower day-to-day variability in blood glucose-lowering effect compared with insulin glargine $100 \mathrm{U} / \mathrm{mL}[4,5]$ and $300 \mathrm{U} / \mathrm{mL}$ [6]. Treat-to-target, randomized controlled trials (RCTs) have demonstrated that insulin degludec is associated with a reduced risk of hypoglycemia compared to insulin glargine U100, with equivalent glycemic control, in patients with either T1DM or T2DM [7-10].

In recent years, the importance of complementing clinical trial results with real-world evidence has been widely recognized, with the aim of assessing the generalizability of results from RCTs to wider, less selected populations $[11,12]$. Several real-world studies have evaluated the effectiveness and safety of insulin degludec [13-24] in routine clinical practice. However, none of these studies have prospectively collected information on hypoglycemic events. Retrospective data collection entails a particular risk of recall bias or incomplete reporting of such events. The ReFLeCT observational, prospective study was designed to overcome these limitations [25]. Global results from ReFLeCT confirmed that switching treatment to insulin degludec from other basal insulins reduces the rates of hypoglycemia patients with T1DM or T2DM, while allowing better glycemic control in those with T2DM [25].

In the Italian setting, prospective data on the incidence of hypoglycemia and the effects of 
different insulin treatment regimens are limited. In the ReFLeCT study, a large proportion of patients were recruited in Italy. The aim of this study was to analyze the data of the Italian participants in ReFLeCT in order to assess the effectiveness and safety of switching to insulin degludec from other basal insulins in the routine clinical care of adults with T1DM or T2DM attending diabetes centers.

\section{METHODS}

\section{Study Design and Population}

The design of the ReFLeCT study has already been described in detail elsewhere [25]. Briefly, ReFLeCT was a 12-month, multicenter, prospective, non-interventional study (ClinicalTrials.gov ID: NCT02392117) conducted across seven European countries (Italy, Denmark, the Netherlands, Spain, Sweden, Switzerland, and the UK) between March 2015 and March 2018. The aim of the study was to assess the safety and effectiveness of switching the treatment of adults with T1DM or T2DM from another basal insulin to insulin degludec once daily. The decision to initiate insulin degludec treatment with the patient occurred independently of patient enrollment in the study. Patients were followed for 4 weeks before (baseline period) and up to 12 months after being switched to insulin degludec (Fig. 1). At the end of the 4-week baseline period, the treating physicians re-evaluated each patient and confirmed or refuted the decision to switch to insulin degludec. Other than their basal insulin, patients could continue to use their other background glucose-lowering therapies. Change in dose, dose interval, and add-on or removal of bolus insulin and other antidiabetic drugs were at the discretion of the treating physician.

Clinical, laboratory, and patient-reported outcome data were collected as part of routine clinical practice in the following timeframes during the 12-month follow-up period: 0 months ( +14 days), 3 months ( \pm 45 days), 6 months ( \pm 45 days), 9 months ( \pm 45 days), and 12 months ( \pm 45 days). Patients only attended visits that were part of routine clinical practice; therefore, not all patients were expected to attend all visits. The most recent values of hemoglobin $\mathrm{A}_{1 \mathrm{c}}\left(\mathrm{HbA}_{1 \mathrm{c}}\right)$, fasting plasma glucose (FPG), and body weight were recorded at each visit. The Diabetes Treatment Satisfaction Questionnaire status version (DTSQ-s) [26] and the Short Form-36 (SF-36® v2) [27] health status survey were completed by patients at each visit.

Patients were provided with up to five studyspecific diaries. The first diary covered the 4-week baseline, pre-switch period and the remaining diaries covered the 4-week period prior to each subsequent visit. The diaries were used to record information on basal insulin dose and time of administration. The following information on every hypoglycemic event was also recorded: date/time of event; if it was selftreated or required assistance; which symptoms were experienced; blood glucose (BG) value (if recorded); resource use (e.g., additional visits or access to emergency department).

In accordance with the requirements of the Declaration of Helsinki, informed consent was obtained from all patients [28]. All procedures followed were in accordance with the ethical standards of the responsible committee on human experimentation (institutional and national) and with the Helsinki Declaration of 1964, as revised in 2013. The master ethics committee of the main center was Comitato Etico Palermo 1, Azienda Ospedaliera

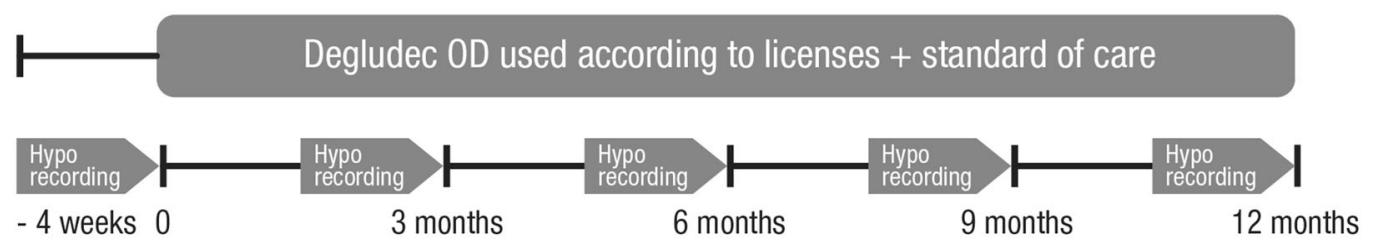

Fig. 1 Study design. $O D$ Once daily 
Universitaria Policlinico Giaccone. The complete list of Ethics Committees are given in the Electronic Supplementary Material (ESM).

In this subanalysis of the ReFLeCT study we considered only the Italian cohort, which represented 27 and $52 \%$ of the patients with T1DM and T2DM, respectively, in the ReFLeCT study.

\section{Study Endpoints}

The primary endpoint was the change from baseline in the overall rates of hypoglycemic events (number of events per patient-year). Overall hypoglycemia was defined as any hypoglycemic event recorded in the diary, irrespective of symptoms, BG measurement, and time of day [29].

Secondary endpoints included change from the baseline period in the number of severe, non-severe, nocturnal, severe or BG-confirmed, and severe or BG-confirmed symptomatic hypoglycemic events. Severe hypoglycemia was defined as an event requiring the assistance of another person to actively administer carbohydrate, glucagon, or other corrective actions [30]. Non-severe hypoglycemia was defined as either an event with or without symptoms accompanied by a BG measurement $\leq 3.9 \mathrm{mmol} / \mathrm{L}$ $(70 \mathrm{mg} / \mathrm{dL})$, or an event with symptoms not accompanied by a BG measurement but assumed to be caused by a BG value $\leq$ $3.9 \mathrm{mmol} / \mathrm{L} \quad(70 \mathrm{mg} / \mathrm{dL})$. Nocturnal hypoglycemia was defined as an event (either severe or non-severe) occurring between 0001 and 0559 (inclusive) hours, regardless of whether the patient was awake or woken up. Other secondary endpoints included the changes from baseline in $\mathrm{HbA}_{1 \mathrm{c}}$, FPG, daily insulin dose (total, basal and bolus), body weight, health-related quality of life questionnaire scores (assessed using DTSQ-s and SF-36 ${ }^{\circledR}$ v2), and flexibility in timing of doses after 12 months of treatment with insulin degludec.

The DTSQ-s consists of eight questions and investigates how satisfied patients are with their treatment [26]. A total score is produced (range 0-36), with higher values indicating higher treatment satisfaction. The questionnaire also contains a separate question assessing perceived frequency of hypoglycemia, with a lower score indicating a lower perception of hypoglycemia $(0=$ never; $6=$ most of the time).

The SF-36 ${ }^{\circledR}$ v2 is a widely used questionnaire assessing the patient's general health status. It includes 36 questions that cover eight different domains; two summary scores can also be computed (Physical Component Score and Mental Component Score) [27]. Higher scores indicate better health status, with a score of 50 and a standard deviation (SD) of 10 representing the values for the general population.

\section{Statistical Analysis}

All the analyses were done by diabetes type and were based on the full analysis set, including all patients who received at least one dose of insulin degludec. Baseline characteristics were summarized as the mean and SD or percentage, as appropriate. Hypoglycemia endpoints were analyzed using negative binomial regression specifying a log-transformed follow-up time offset term. Baseline covariates included period (pre/post-switch to insulin degludec), age, gender, $\mathrm{HbA}_{1 \mathrm{c}}$, diabetes duration, and body mass index (BMI). For patients with T2DM, additional covariates included use of bolus insulin (yes/no) and sulfonylurea or glinides (yes/no), as these medications could impact on the rates of hypoglycemia. The analyses compared the 12-month follow-up period with the 4-week baseline period. Results are expressed as incidence rate ratios (IRRs) with 95\% confidence intervals $(95 \% \mathrm{CI})$.

The changes in $\mathrm{HbA}_{1 \mathrm{c}}$, FPG, body weight, and insulin dose were estimated using analysis of covariance with a mixed model for repeated measures. Covariates included visit, baseline value, age, gender, BMI, and diabetes duration. For patients with T2DM, additional time-varying covariates included the use of bolus insulin (yes/no; omitted from the bolus insulin dose analysis), sulfonylurea or glinides (yes/no), glucagon-like peptide-1 receptor agonist (yes/ no), and other antidiabetic drugs (yes/no). The results of the SF-36® v2 [27] and DTSQ-s [26] were scored as per questionnaire instructions, and the mean change from baseline (95\% CI) 
was summarized. A difference of more than half a standard deviation of the baseline score is considered to be a meaningful change [30]. The number of patients who at 12 months had used the flexibility option for timing of doses was summarized using percentages. All statistical tests were two-tailed with a significance level of $P<0.05$. All statistical analyses were performed using SAS version 9.3 or higher (SAS Institute, Cary, NC, USA).

\section{RESULTS}

\section{Baseline Characteristics}

Overall, 148 patients with T1DM and 311 patients with T2DM were enrolled in Italy. Baseline characteristics are shown in Table 1. At baseline, patients with T1DM had a mean age of 45.7 years, $55.4 \%$ were male, the mean duration of diabetes was 18.1 years, and the mean $\mathrm{HbA}_{1 \mathrm{c}}$ was $8.0 \% ; 54.7 \%$ were defined as prone to hypoglycemia and $20.9 \%$ had an $\mathrm{HbA}_{1 \mathrm{c}}<7.0 \%$. At baseline, patients in the T2DM group had a mean age of 65.7 years, $60.1 \%$ were male, the mean duration of diabetes was 19.2 years, and the mean $\mathrm{HbA}_{1 \mathrm{c}}$ was $8.2 \% ; 17.7 \%$ had an $\mathrm{HbA}_{1 \mathrm{c}}<7.0 \%$, and $50.2 \%$ were considered to be prone to hypoglycemia.

The majority of patients switched from glargine U100 to insulin degludec in both the T1DM group (83.1\%) and the T2DM group (70.7\%) (Table 1). The most common reasons for switching were the need to improve BG control (68.9\% in T1DM; $75.9 \%$ in T2DM) and concern about hypoglycemia $(62.8 \%$ in T1DM; $32.8 \%$ in $\mathrm{T} 2 \mathrm{DM}) ; 13.5 \%$ of patients with T1DM and $7.7 \%$ of patients with T2DM switched to insulin degludec because their current regimen was considered to be too restrictive.

\section{Hypoglycemia}

In patients with T1DM, significantly lower rates of overall hypoglycemia were reported during the follow-up period versus the 4-week baseline period (IRR 0.69, 95\% CI 0.57-0.82) (Fig. 2a). Similarly, significantly lower rates of non-severe
(IRR 0.72, 95\% CI 0.60-0.85) and nocturnal (IRR 0.46, 95\% CI 0.41-0.69) hypoglycemic episodes were registered (Fig. 2b, c). In patients with T2DM, significantly lower rates of overall hypoglycemia were documented (IRR 0.40, 95\% CI 0.29-0.55) (Fig. 2a), andsignificantly lower rates of non-severe (IRR 0.4, 95\% CI 0.34-0.63) and nocturnal (IRR 0.27, 95\% CI 0.09-0.86 hypoglycemia were also observed during the follow-up period versus the baseline period (Fig. 2b,c). Due to the low number of severe hypoglycemia events, no comparative statistics were performed (Table 2).

\section{Glycemic Control}

In patients with T1DM, a statistically significant reduction in $\mathrm{HbA}_{1 \mathrm{c}}$ was documented during the follow-up period versus the baseline period (estimated treatment difference [ETD] $-0.35 \%$, 95\% CI -0.50 to $-0.20 ; P<0.001$ ) (Fig. 3 ). A non-statistically significant reduction in FPG was detected (ETD - $0.35 \mathrm{mmol} / \mathrm{L}, 95 \% \mathrm{CI}-$ 1.12 to $0.43 ; P=0.38$ ) (Fig. 3 ). After 12 months, the proportions of patients reaching the $\mathrm{HbA}_{1 \mathrm{c}}$ target of $<7.0 \%$ or $<7.5 \%$ were 31.1 and $45.3 \%$, respectively.

In patients with $\mathrm{T} 2 \mathrm{DM}, \mathrm{HbA}_{1 \mathrm{c}}$ decreased significantly during the 12-month follow-up period versus the 4-week baseline period (ETD - 0.45\%, 95\% CI -0.58 to -0.31 ; $P<0.001$ ) (Fig. 3). The reduction in FPG was also statistically significant (ETD $-0.90 \mathrm{mmol} /$ L, 95\% CI -1.21 to $-0.59 ; P<0.001$ ) (Fig. 3). After 12 months the proportions of patients reaching the $\mathrm{HbA}_{1 \mathrm{c}}$ target of $<7.0 \%$ or $<7.5 \%$ were 26.4 and $47.9 \%$, respectively.

\section{Insulin Dose and Body Weight}

In patients with T1DM, the average (SD) basal insulin dose was 19.7 (8.3) U/day during the baseline period and 19.3 (8.7) U/day after 12 months of follow-up (change from baseline $-0.26,95 \% \mathrm{CI}-1.29$ to 0.78 ). The average rapid insulin dose decreased from 31.2 (21.9) to 24.3 (14.1) U/day (change from baseline $-4.56,95 \% \mathrm{CI}-7.42$ to -1.70$)$.

In patients with T2DM, the average basal insulin dose was 23.2 (10.5) U/day during the 
Table 1 Baseline patient characteristics

\begin{tabular}{lll}
\hline Characteristic & T1DM group & T2DM group \\
\hline Full analysis set $(N)$ & 148 & 311 \\
Male (\% of patients) & 55.4 & 60.1 \\
Age (years) & $45.7 \pm 16.8$ & $65.7 \pm 8.9$ \\
Weight $(\mathrm{kg})$ & $71.7 \pm 15.4$ & $83.3 \pm 17.1$ \\
Body mass index $\left(\mathrm{kg} / \mathrm{m}^{2}\right.$ ) & $25.3 \pm 4.5$ & $30.5 \pm 5.9$ \\
Duration of diabetes (years) & $18.1 \pm 12.6$ & $19.2 \pm 10.5$ \\
Hemoglobin A lc $\left.^{2}\right)$ & $8.0 \pm 1.3$ & $8.2 \pm 1.4$ \\
Fasting plasma glucose (mmol/L) & $8.7 \pm 3.6$ & $9.1 \pm 3.0$ \\
Glucose-lowering therapy (\% of patients) & & 3.5 \\
Glucagon-like peptide-1 receptor agonist (GLP1-RA) & 0.0 & 8.0 \\
Sulfonylureas & 0.0 & 1.3 \\
Thiazolidinediones & 0.0 & 6.4 \\
Dipeptidyl peptidase 4 ( DPP-4) inhibitors & 0.0 & 9.0 \\
Sodium-glucose co-transporter-2 (SGLT-2) inhibitors & 0.0 & 40.2 \\
Metformin & 7.4 & 66.6 \\
Bolus insulin & 86.5 & 85.9 \\
Basal insulin & 90.5 & $23.5 \pm 12.3$ \\
Total daily dose of basal insulin (U/day) & $20.0 \pm 8.7$ & $32.5 \pm 16.9$ \\
Total daily dose of bolus insulin (U/day) & $27.4 \pm 18.5$ &
\end{tabular}

Values in table are presented as the mean \pm standard deviation, unless denoted otherwise T1DM Type 1 diabetes mellitus, T2DM type $2 \mathrm{DM}$

baseline period and 23.7 (12.2) U/day after 12 months of follow-up (change from baseline $0.76,95 \% \mathrm{CI}-0.05$ to 1.57 ). The average rapid insulin dose was 30.9 (18.1) U/day during the baseline period and 30.6 (20.0) U/day after 12 months (change from baseline $-0.87,95 \%$ CI -3.01 to 1.27 ).

Body weight significantly increased in patients with T1DM from a mean of 71.5 (15.3) $\mathrm{kg}$ at baseline to 72.4 (14.6) $\mathrm{kg}$ after 12 months (ETD $0.83 \mathrm{~kg}$, 95\% CI $0.16-1.50$; $P=0.015)$. In patients with T2DM, mean body weight was $83.0(17.1) \mathrm{kg}$ at baseline and 83.0 (16.7) $\mathrm{kg}$ after 12 months of follow-up (ETD $0.19 \mathrm{~kg}, 95 \% \mathrm{CI}-0.48$ to $0.86 ; P=0.57$ ).

\section{Patient-Reported Outcomes}

A clinically meaningful increase in the DTSQ-s score from baseline to 12 months was documented for both T1DM and T2DM patients (Fig. 4; ESM Table 1). Perception of hypoglycemia decreased significantly in patients with either diabetes type (ESM Table 1). The results from the SF-36® v2 survey showed a statistically significant improvement in roleemotional, mental health, and mental component summary scores in patients with T1DM (ESM Table 1). In patients with T2DM, an improvement in the bodily pain dimension was documented (ESM Table 2). 

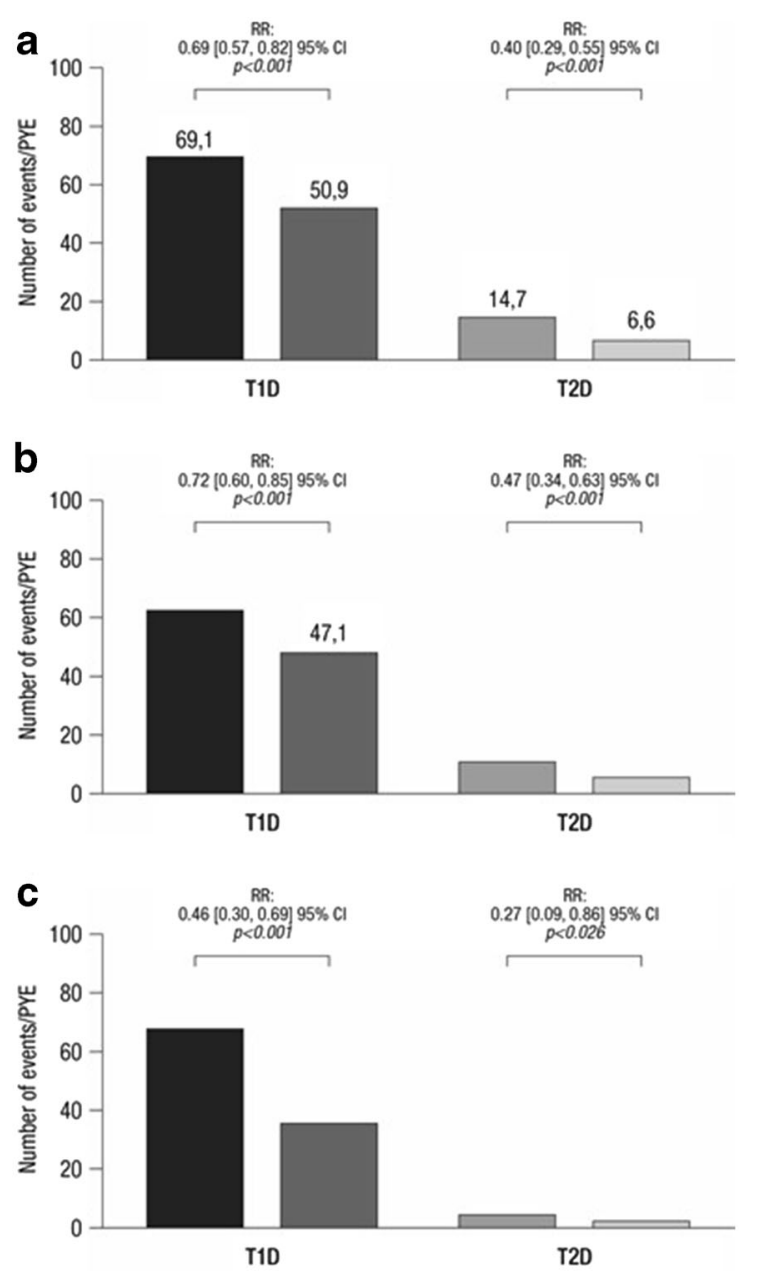

Fig. 2 Changes from baseline in rates of overall hypoglycemic events (a), non-severe hypoglycemic events (b), and nocturnal hypoglycemic events (c). CI Confidence interval, PYE patient-year, $R R$ rate ratio, T1D/T2D type $1 /$ type 2 diabetes mellitus

After 12 months, 31.9\% patients with T1DM and $12.2 \%$ of those with T2DM used the specific flexibility option one or more times. Finally, at the end of the follow-up, 99\% of T1DM patients and $100 \%$ of $\mathrm{T} 2 \mathrm{DM}$ patients declared they preferred insulin degludec to their previous treatment, and $100 \%$ of both the T1DM and T2DM patients stated that they preferred the Flextouch ${ }^{\circledR}$ pen (Novo Nordisk, Bagsværd, Denmark) to the previous device.

\section{DISCUSSION}

ReFLeCT was a prospective, real-world study evaluating the safety and effectiveness of insulin degludec in routine clinical care. The analysis relative to Italian patients with T1DM or T2DM confirmed that switching to insulin degludec from other basal insulins was associated with significant reductions in the incidence of overall, non-severe, and nocturnal hypoglycemia, along with improved glycemic control and treatment satisfaction. The comparison of the rate of hypoglycemia in our study with that of other studies is made difficult by the different methodology used for data collection (prospective vs. retrospective) and the different definitions of hypoglycemia. In one large, retrospective Italian study [31, 32], the incidence of symptomatic hypoglycemia was 53.3, 10.8, and 18.4 events per patient-year among patients with T1DM and among patients with T2DM treated with a basal-oral scheme or with multiple daily insulin injections, respectively. These figures are very close to the rates of overall hypoglycemia found in our study. Other observational studies generally reported a lower incidence of hypoglycemia, probably as a consequence of a suboptimal quantification of episodes related to the retrospective study design $[17,24]$, such as the EU-TREAT study, which was based on chart review [14]. However, in our study the selection of patients who would be candidates for switching to insulin degludec could be at least partially responsible for the higher rate of hypoglycemia. Furthermore, concern about hypoglycemia was a common reason for starting insulin degludec therapy, thereby suggesting that patients with frequent hypoglycemia events may be over-represented in the study.

Under routine clinical practice conditions, the switch from another basal insulin to insulin degludec in patients with T2DM made it possible to achieve better metabolic control while reducing the incidence of hypoglycemia without weight gain. In patients with T1DM, the reduction in the number of hypoglycemia events was associated with a decrease in $\mathrm{HbA}_{1 \mathrm{c}}$ levels and in the dose of rapid-acting insulin, 
Table 2 Changes from baseline in number of hypoglycemia episodes

\begin{tabular}{|c|c|c|c|c|c|c|}
\hline \multirow{2}{*}{$\begin{array}{l}\text { Patient } \\
\text { group }\end{array}$} & \multicolumn{3}{|l|}{ Baseline } & \multicolumn{3}{|c|}{ Follow-up } \\
\hline & $\begin{array}{l}\text { Number } \\
\text { of } \\
\text { episodes }\end{array}$ & $\begin{array}{l}\text { Number of patients } \\
\text { with } \geq 1 \text { episodes } \\
\text { (\%) }\end{array}$ & $\begin{array}{l}\text { Estimated } \\
\text { annual } \\
\text { incidence rate }\end{array}$ & $\begin{array}{l}\text { Number } \\
\text { of } \\
\text { episodes }\end{array}$ & $\begin{array}{l}\text { Number of patients } \\
\text { with } \geq 1 \text { episodes } \\
\text { (\%) }\end{array}$ & $\begin{array}{l}\text { Estimated } \\
\text { annual } \\
\text { incidence rate }\end{array}$ \\
\hline \multicolumn{7}{|c|}{ T1DM group } \\
\hline Overall & 733 & $104(74.3)$ & 69.1 & 1492 & $98(69.5)$ & 50.9 \\
\hline $\begin{array}{l}\text { Non- } \\
\text { severe }\end{array}$ & 655 & $101(72.1)$ & 61.8 & 1378 & $98(69.5)$ & 47.1 \\
\hline Nocturnal & 71 & 39 (27.9) & 6.7 & 100 & $45(31.9)$ & 3.4 \\
\hline $\begin{array}{l}\text { ADA- } \\
\text { defined } \\
\text { severe }\end{array}$ & 1 & $1(0.7)$ & 0.1 & 0 & 0 & 0.0 \\
\hline \multicolumn{7}{|c|}{ T2DM group } \\
\hline Overall & 301 & $89(33.1)$ & 14.7 & 403 & $81(27.5)$ & 6.6 \\
\hline $\begin{array}{l}\text { Non- } \\
\text { severe }\end{array}$ & 217 & $81(30.1)$ & 10.6 & 338 & $74(25.1)$ & 5.6 \\
\hline Nocturnal & 9 & $7(2.6)$ & 0.4 & 14 & $7(2.4)$ & 0.2 \\
\hline $\begin{array}{l}\text { ADA- } \\
\text { defined } \\
\text { severe }\end{array}$ & 0 & 0 & 0.0 & 1 & $1(0.3)$ & 0.0 \\
\hline
\end{tabular}

ADA American Diabetes Association

with a minimal increase in body weight. The very modest, though significant, increase in body weight in patients with T1D is not consistent with trial results [33]. Speculative explanations include: (1) the prior use of detemir, which is associated with less weight gain, in a subset of patients; (2) the correction of a relative hypo-insulinization with the prior basal regimen; (3) differences in the induction of satiety.

The findings of our study are reassuring with regard to the effectiveness and safety profile of insulin degludec, suggesting that more effective titration schemes could be adopted to increase the proportion of patients reaching the desired metabolic targets. In this respect, the observation that $>50 \%$ of the patients with T1DM or T2DM in our study still had $\mathrm{HbA}_{1 \mathrm{c}}$ levels $>7.5 \%$ while the basal insulin dose was almost unchanged 12 months after the switch to insulin degludec deserves particular attention. When compared to results obtained in the entire multinational ReFLeCT cohort, data from the Italian subset depict a particularly consistent efficacy and safety profile of insulin degludec. For T1DM and T2DM, the main results of the global analysis were in line, but reductions in the rates of hypoglycemia tended to be greater for the Italian cohort, as was improvement in HbA1c. It is worth noting that pooling data from different countries can mask country-specific patterns. In fact, the use of certain drugs can follow different local routine practices. This can be particularly true for studies like ReFLeCT, in which patient selection, decision to initiate insulin degludec, and follow-up schedule followed local guidelines and resource availability. Therefore, analysis of the Italian ReFLeCT sub-cohort, the single- 

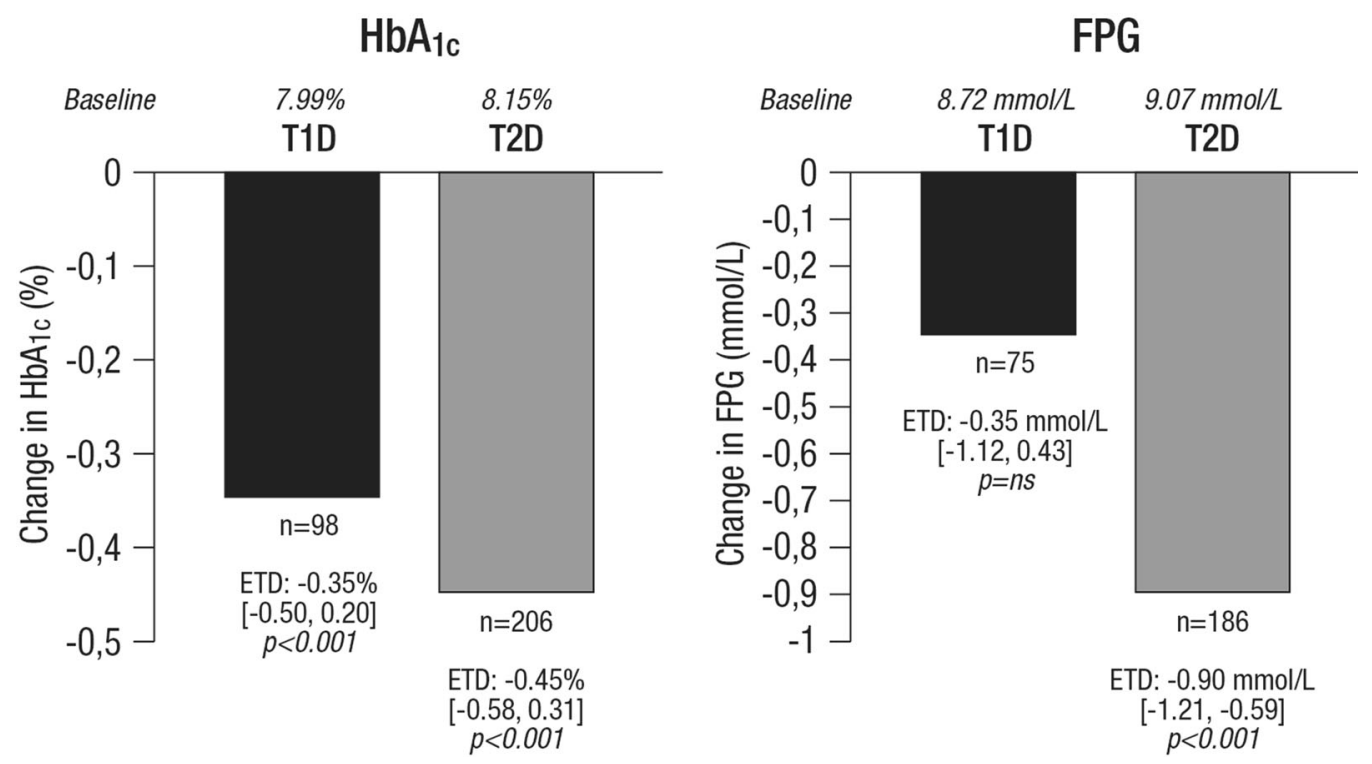

Fig. 3 Change from baseline in hemoglobin $\mathrm{A}_{1 \mathrm{c}}\left(H b A_{1 c}\right)$ and fasting plasma glucose $(F P G)$ levels. Values in square brackets are the $95 \%$ CI. ETD Estimated treatment difference, $n s$ non-statistically significant

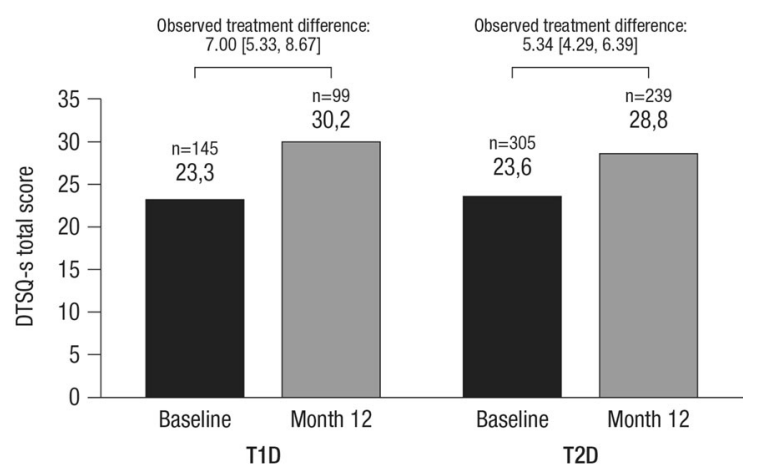

Fig. 4 Change from baseline in the Diabetes Treatment Satisfaction Questionnaire status version (DTSQ-s) total score

country cohort most represented, is particularly relevant for demonstrating the efficacy and safety of switching from other basal insulins to insulin degludec in a homogeneous healthcare setting.

Switching to insulin degludec was also associated with a significant improvement in patient satisfaction with the treatment. This is likely to be related not only to its effectiveness and safety but also to greater flexibility in time of administration: one in three patients with T1DM used the specific flexibility option at least once during follow-up. These findings are important, considering that treatment satisfaction is fundamental to ensuring patient adherence to therapy and that the perception of barriers to treatment plays an important role in influencing diabetes-related distress [34].

Our study has its strengths and limitations. Among the strengths, the prospective study design allowed a more accurate estimate of hypoglycemia burden and a comprehensive evaluation of safety, effectiveness, and patientcentered measures. Among the limitations, a "study effect" cannot be ruled out and could be at least partially responsible for the positive findings. However, the reduction in the number of hypoglycemic events documented in this study is consistent with the results of RCTs and other real-world studies showing lower rates of hypoglycemia than the comparator $[7-9,14,18]$.

\section{CONCLUSIONS}

In conclusion, this study demonstrated the effectiveness and safety of switching to insulin degludec from other basal insulins in the routine clinical care of adults with T1DM or T2DM attending diabetes centers in Italy. 


\section{ACKNOWLEDGEMENTS}

We wish to thank the participants of the study.

Funding. The entire conduct of the study was sponsored by Novo Nordisk A/S, including the Rapid Service Fee.

Editorial Assistance. Editorial assistance was provided by Alessandra Palmieri of Airon Communications, Milan, Italy, with financial support from Novo Nordisk, in compliance with international guidelines for good publication practice.

Authorship. All named authors meet the International Committee of Medical Journal Editors (ICMJE) criteria for authorship for this article, take responsibility for the integrity of the work as a whole, and have given their approval for this version to be published.

Disclosures. Gian Paolo Fadini received lecture fees or grant support from Abbott, AstraZeneca, Boehringer, Lilly, Merck-Sharp-Dome, Mundipharma, Novartis, Novo Nordisk, Sanofi, and Servier. Laura Salvi is an employee of Novo Nordisk SpA (Rome, Italy). Antonio Nicolucci received research grants from Aboca, AstraZeneca, Medtronic, Novo Nordisk, Sanofi, Shionogi, and Sobi. Theras, Carla Giordano has nothing to disclose.

Compliance with Ethics Guidelines. In accordance with the requirements of the Declaration of Helsinki, informed consent was obtained from all patients [28]. All procedures followed were in accordance with the ethical standards of the responsible committee on human experimentation (institutional and national) and with the Helsinki Declaration of 1964, as revised in 2013. The master ethics committee of the main center was Comitato Etico Palermo 1, Azienda Ospedaliera Universitaria Policlinico Giaccone. The complete list of Ethics Committees are given in the Electronic Supplementary Material (ESM).

Data Availability. The datasets generated during and/or analyzed during the current study are available from the corresponding author on reasonable request.

Open Access. This article is licensed under a Creative Commons Attribution-NonCommercial 4.0 International License, which permits any non-commercial use, sharing, adaptation, distribution and reproduction in any medium or format, as long as you give appropriate credit to the original author(s) and the source, provide a link to the Creative Commons licence, and indicate if changes were made. The images or other third party material in this article are included in the article's Creative Commons licence, unless indicated otherwise in a credit line to the material. If material is not included in the article's Creative Commons licence and your intended use is not permitted by statutory regulation or exceeds the permitted use, you will need to obtain permission directly from the copyright holder. To view a copy of this licence, visit http:// creativecommons.org/licenses/by-nc/4.0/.

\section{REFERENCES}

1. Cryer PE. The barrier of hypoglycemia in diabetes. Diabetes. 2008;57:3169-76.

2. Workgroup on Hypoglycemia, American Diabetes Association. Defining and reporting hypoglycemia in diabetes: a report from the American Diabetes Association Workgroup on Hypoglycemia. Diabetes Care. 2005;28:1245-9.

3. Khunti K, Alsifri S, Aronson R, et al. Impact of hypoglycaemia on patient reported outcomes from a global, 24-country study of 27,585 people with type 1 and insulin treated type 2 diabetes. Diabetes Res Clin Pract. 2017;130:121-9.

4. Novo Nordisk A/S. Tresiba (Insulin Degludec) summary of product characteristics. https://www. ema.europa.eu/en/documents/productinformation/tresiba-epar-product-information_en. pdf. Accessed Dec 2019.

5. Heise T, Hermanski L, Nosek L, Feldman A, Rasmussen S, Haahr H. Insulin degludec: four times lower pharmacodynamic variability than insulin glargine under steady-state conditions in type 1 diabetes. Diabetes Obes Metab. 2012;14:859-64. 
6. Heise T, Norskov M, Nosek L, Kaplan K, Famulla S, Haahr HL. Insulin degludec: lower day-to day and within-day variability in pharmacodynamic response compared with insulin glargine $300 \mathrm{U} / \mathrm{mL}$ in type 1 diabetes. Diabetes Obes Metab. 2017;19: 1032-9.

7. Ratner RE, Gough SC, Mathieu C, et al. Hypoglycaemia risk with insulin degludec compared with insulin glargine in type 2 and type 1 diabetes: a preplanned meta-analysis of phase 3 trials. Diabetes Obes Metab. 2013;15:175-84.

8. Lane W, Bailey TS, Gerety G, et al. Effect of insulin degludec vs insulin glargine U100 on hypoglycemia in patients with type 1 diabetes: the SWITCH 1 randomized clinical trial. JAMA. 2017;318:33-44.

9. Wysham C, Bhargava A, Chaykin L, et al. Effect of insulin degludec vs insulin glargine U100 on hypoglycemia in patients with type 2 diabetes: the SWITCH 2 randomized clinical trial. JAMA. 2017;318:45-56.

10. Marso SP, McGuire DK, Zinman B, et al. Efficacy and safety of degludec versus glargine in type 2 diabetes. N Engl J Med. 2017;377:723-32.

11. Yang W, Zilov A, Soewondo P, Bech OM, Sekkal F, Home PD. Observational studies: going beyond the boundaries of randomized controlled trials. Diabetes Res Clin Pract. 2010;88(Suppl 1):S3-9.

12. Sherman RE, Anderson SA, Dal Pan GJ, et al. Realworld evidence-what is it and what can it tell us? N Engl J Med. 2016;375:2293-7.

13. Evans M, McEwan P, Foos V. Insulin degludec early clinical experience: does the promise from the clinical trials translate into clinical practice-a casebased evaluation. J Med Econ. 2015;18:96-105.

14. Siegmund T, Tentolouris N, Knudsen ST, et al. A European, multicentre, retrospective, non-interventional study (EU-TREAT) of the effectiveness of insulin degludec after switching basal insulin in a population with type 1 or type 2 diabetes. Diabetes Obes Metab. 2018;20:689-97.

15. Landstedt-Hallin L. Changes in $\mathrm{HbA}_{1 \mathrm{c}}$, insulin dose and incidence of hypoglycemia in patients with type 1 diabetes after switching to insulin degludec in an outpatient setting: an observational study. Curr Med Res Opin. 2015;31:1487-93.

16. Galasso S, Facchinetti A, Bonora BM, et al. Switching from twice-daily glargine or detemir to oncedaily degludec improves glucose control in type 1 diabetes. An observational study. Nutr Metab Cardiovasc Dis. 2016;26:1112-9.
17. Bohn B, Zimmermann A, Wagner C, et al. Real-life experience of patients starting insulin degludec. A multicenter analysis of 1064 subjects from the German/Austrian DPV registry. Diabetes Res Clin Pract. 2017;129:52-8.

18. Kaku K, Wolden ML, Hyllested-Winge J, Nortoft E. Insulin degludec in clinical practice: a review of japanese real-world data. Diabetes Ther. 2017;8: 189-95.

19. Ghosal S, Sinha B, Gangopadhyay KK. Insulin glargine versus insulin degludec in patients failing on oral therapy in type 2 diabetes: a retrospective real world comparative data from India. Diabetes Metab Syndr. 2016;10:161-5.

20. Kobuke K, Yoneda M, Nakanishi S, Ohno H, Maeda S, Egusa G. Efficacy and safety of insulin degludec in Japanese patients with type 1 and type 2 diabetes: 24 -week results from the observational study in routine clinical practice. J Diabetes Investig. 2016;7:94-9.

21. Urakami T, Kuwabara R, Aoki M, Okuno M, Suzuki J. Efficacy and safety of switching from insulin glargine to insulin degludec in young people with type 1 diabetes. Endocr J. 2016;63:159-67.

22. Suzuki J, Yamakawa T, Nagakura J, Shigematsu E, Kadonosono K, Terauchi Y. Efficacy of switching from insulin glargine to insulin degludec in patients with type 1 diabetes: a 16-week retrospective study. Diabetol Int. 2017;8:45-51.

23. Shimoda S, Sato M, Sekigami T, et al. A 1-year, prospective, observational study of Japanese outpatients with type 1 and type 2 diabetes switching from insulin glargine or detemir to insulin degludec in basal-bolus insulin therapy (Kumamoto Insulin Degludec Observational study). J Diabetes Investig. 2016;7:703-10.

24. Tibaldi J, Hadley-Brown M, Liebl A, et al. A comparative effectiveness study of degludec and insulin glargine $300 \mathrm{U} / \mathrm{mL}$ in insulin-naïve patients with type 2 diabetes. Diabetes Obes Metab. 2018;21: 1001-9.

25. Fadini GP, Feher M, Hansen TK, et al. Switching to degludec from other basal insulins is associated with reduced hypoglycemia rates: a prospective study. J Clin Endocrinol Metab. 2019;104:5977-90.

26. Bradley C (editor). The Diabetes Treatment Satisfaction Questionnaire. DTSQ. In: Bradley C, editor. Handbook of psychology and diabetes: a guide to psychological measurement in diabetes research and practice. Chur: Harwood Academic Publishers; 1994. p. 111-32. 
27. Ware JE, Kosinski M, Bjorner JB, Turner-Bowker DM, Maruish ME. User's manual for the SF-36 v2 health survey. Lincoln: QualityMetric; 2007.

28. World Medical Association. World Medical Association Declaration of Helsinki: ethical principles for medical research involving human subjects. JAMA. 2013;310:2191-4.

29. Seaquist ER, Anderson J, Childs B, et al. Hypoglycemia and diabetes: a report of a workgroup of the American Diabetes Association and the Endocrine Society. Diabetes Care. 2013;36:1384-95.

30. Norman GR, Sloan JA, Wyrwich KW. Interpretation of changes in health-related quality of life: the remarkable universality of half a standard deviation. Med Care. 2003;41:582-92.
31. Giorda CB, Ozzello A, Gentile S, et al. Incidence and correlates of hypoglycemia in type 2 diabetes. The HYPOS-1 study. J Diabetes Metab. 2014;5:344.

32. Giorda CB, Ozzello A, Gentile S, et al. Incidence and risk factors for severe and symptomatic hypoglycemia in type 1 diabetes. Results of the HYPOS-1 study. Acta Diabetol. 2015;52:845-53.

33. Holmes RS, Crabtree E, McDonagh MS. Comparative effectiveness and harms of long-acting insulins for type 1 and type 2 diabetes: a systematic review and meta-analysis. Diabetes Obes Metab. 2019;21: 984-92.

34. Pintaudi B, Lucisano G, Gentile S, et al. Correlates of diabetes-related distress in type 2 diabetes: findings from the benchmarking network for clinical and humanistic outcomes in diabetes (BENCH-D) study. J Psychosom Res. 2015;79:348-54. 